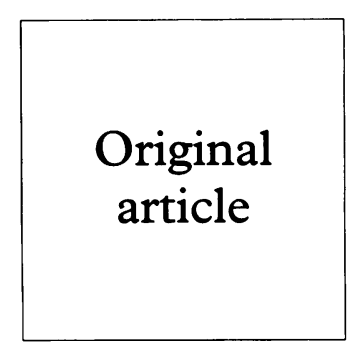

\title{
Voluntary confidential HIV testing of STD patients in Switzerland, 1990-5: HIV test refusers cause different biases on HIV prevalences in heterosexuals and homo/bisexuals
}

\author{
W J Paget, M Zwahlen, A R Eichmann, and the Swiss Network of Dermatovenereology \\ Policlinics ${ }^{\star}$
}

Objectives: To monitor the prevalence of HIV infection among heterosexual and male homo/bisexual STD patients and assess the effect of HIV test refusers on the HIV prevalences.

Methods: A voluntary confidential HIV test was offered to all people diagnosed with an STD at the Swiss Network of Dermatovenereology Policlinics (SNDP) between July 1990 and June 1995. Anonymous sociodemographic and behavioural information was collected for each patient regardless of whether $\mathrm{s} /$ he accepted or refused the HIV test.

Results: The prevalence of HIV was $1.6 \%$ among heterosexuals and $22 \cdot 4 \%$ homo/bisexual men and remained stable between July 1990 and June 1995 . Refusal rates were $17 \cdot 5 \%$ among heterosexuals and $16.0 \%$ among homo/bisexual men and did not change significantly over time. To assess the potential effect of HIV test refusers on the monitored HIV prevalences, we analysed test refusers by multivariate logistic regression. Among heterosexuals, refusal rates were significantly higher among patients with relatively low risk behaviours (patients reporting $0-1$ sexual partners in the previous 6 months) while among homo/bisexual men they were significantly higher in those with high risk behaviours (patients reporting 10 or more sexual partners in the previous 6 months).

Conclusions: We found high and stable HIV prevalences among patients treated for an STD at the SNDP. It appears that HIV test refusers biased HIV prevalences among heterosexuals and homo/bisexual men in different directions: in heterosexuals HIV prevalences were overestimated and in homo/bisexuals they were underestimated. A regular analysis of the characteristics of HIV test refusers should be an integral part of surveillance systems which use voluntary confidential HIV testing.

(Genitourin Med 1997;73:444-447)

Keywords: HIV; surveillance; bias

\section{Introduction}

Patients treated for a sexually transmitted disease (STD) are a population at increased risk for HIV infection ${ }^{1}$ and are therefore a particularly relevant group to monitor trends in HIV. The national HIV surveillance system has monitored the prevalence of HIV in this population since January $1990 .^{2}$ Data are collected at the Swiss Network of Dermatovenereology Policlinics (SNDP) which groups together the six policlinics of dermatovenereology which exist in Switzerland. ${ }^{3}$

HIV testing at the SNDP is voluntary and confidential. One of the main disadvantages of using this approach is that participation rates are generally too low for unbiased estimates of HIV prevalence. ${ }^{4}$ Previous studies have found that the use of voluntary confidential HIV testing can lead to a participation bias because those at higher risk of infection are more likely not to contribute specimens and/or a selection bias if clinicians encourage testing in those they consider to be more at risk. ${ }^{45} \mathrm{~A}$ number of countries (for example, the United Kingdom $^{4}$ and United States ${ }^{6}$ ) use unlinked anonymous HIV testing to control for this factor.

This paper describes the prevalence of HIV among STD patients accepting an HIV test and the probable effect of HIV test refusers on the observed HIV prevalences. The latter is particularly relevant to the surveillance of HIV among STD patients in western Europe since most surveillance networks use voluntary confidential HIV testing. In a European Concerted Action Project to monitor HIV prevalences among STD patients, 12 networks use voluntary confidential HIV testing and only three-England and Wales, Scotland, France-use unlinked anonymous testing. ${ }^{7}$

\section{Methods}

SUBJECTS

The SNDP is made up of five university policlinics of dermatovenereology (Basle, Bern, Lausanne, Geneva, and Zurich) and the city policlinic of dermatology at the Triemli Stadtspital, Zurich. The criterion for eligibility into the study was attendance with a new episode of one or more of a selected list of STDs (male urethritis, proctitis, mucopurulent cervicitis, chlamydia, gonorrhoea, herpes genitalia, chancroid, syphilis, genital warts, Trichomonas vaginalis, pelvic inflammatory disease, and pediculosis pubis) provided that the patient had not been seen for any of these STDs in the previous 90 days. $^{7}$ 
Table 1 HIV testing and HIV positives among heterosexuals and male homolbisexuals treated for an STD at the SNDP, fuly 1990-fune 1995

\begin{tabular}{|c|c|c|c|c|c|c|}
\hline & $\begin{array}{l}\text { fuly } 1990 \\
\text { Fune } 1991 \\
n(\%)\end{array}$ & $\begin{array}{l}\text { Fuly 1991- } \\
\text { Fune } 1992 \\
n(\%)\end{array}$ & $\begin{array}{l}\text { fuly } 1992- \\
\text { fune } 1993 \\
n(\%)\end{array}$ & $\begin{array}{l}\text { fuly 1993- } \\
\text { fune } 1994 \\
n(\%)\end{array}$ & $\begin{array}{l}\text { Fuly 1994- } \\
\text { fune 1995 } \\
n(\%)\end{array}$ & $\begin{array}{l}\text { Total for } 5 \\
\text { year period } \\
n(\%)\end{array}$ \\
\hline \multicolumn{7}{|l|}{ Heterosexuals: } \\
\hline $\begin{array}{l}\text { Total } \\
\text { HIV test: }\end{array}$ & 800 & 667 & 479 & 308 & 334 & 2588 \\
\hline $\begin{array}{l}\text { Refused } \\
\text { Accepted }\end{array}$ & $\begin{array}{l}165(20 \cdot 6) \\
635(79 \cdot 4)\end{array}$ & $\begin{array}{l}106(15 \cdot 9) \\
561(84 \cdot 1)\end{array}$ & $\begin{array}{r}72(15 \cdot 0) \\
407(85 \cdot 0)\end{array}$ & $\begin{array}{r}48(15 \cdot 6) \\
260(84 \cdot 4)\end{array}$ & $\begin{array}{r}61(18 \cdot 3) \\
273(81 \cdot 7)\end{array}$ & $\begin{array}{r}452(17 \cdot 5) \\
2136(82 \cdot 5)\end{array}$ \\
\hline HIV positives: & & & & & & \\
\hline HIV infected ${ }^{\star}$ & $13(2 \cdot 0)$ & $7(1 \cdot 2)$ & $2(0.5)$ & $5(1 \cdot 9)$ & $8(2.9)$ & $35(1 \cdot 6)$ \\
\hline $\begin{array}{l}\text { Homo/bisexual men: } \\
\text { Total } \\
\text { HIV test: }\end{array}$ & 85 & 102 & 83 & 69 & 54 & 393 \\
\hline $\begin{array}{l}\text { Refused } \\
\text { Accepted }\end{array}$ & $\begin{array}{l}14(16 \cdot 5) \\
71(83.5)\end{array}$ & $\begin{array}{l}13(12 \cdot 7) \\
89(87 \cdot 3)\end{array}$ & $\begin{array}{l}15(18 \cdot 1) \\
68(81 \cdot 9)\end{array}$ & $\begin{array}{l}10(14.5) \\
59(85.5)\end{array}$ & $\begin{array}{l}11(20 \cdot 4) \\
43(79 \cdot 6)\end{array}$ & $\begin{array}{r}63(16 \cdot 0) \\
330(84 \cdot 0)\end{array}$ \\
\hline $\begin{array}{l}\text { HIV positives: } \\
\text { HIV infected }\end{array}$ & $14(19 \cdot 7)$ & $24(27 \cdot 0)$ & $14(20 \cdot 6)$ & $10(16 \cdot 9)$ & $12(27 \cdot 9)$ & $74(22 \cdot 4)$ \\
\hline
\end{tabular}

$\star \%$ is based on number of test acceptors.

Each STD patient was offered a voluntary confidential HIV test and a standard questionnaire was completed, even if the patient refused the HIV test. Responses were recorded by a medical intern and included information on the patient (for example, age, sex, country of birth), the STD infection, his/her sexuality (for example, sexual orientation, number of sexual partners in the previous 6 months), history of injecting drug use, and the HIV test. Identification numbers rendered the questionnaires anonymous.

The study began in July 1990 following a 6 month pilot phase. This paper presents data collected between July 1990 and June 1995 for heterosexuals $(n=2588)$ and homo/bisexual men $(n=393)$. Of a total 3245 STD patients who attended the SNDP during this period, 264 patients were excluded from the analysis-130 non-Swiss residents, 112 injecting drug users, three female homo/bisexuals, and 19 patients whose risk for HIV infection could not be classified.

\section{STATISTICAL METHODS}

Data entry and analysis were performed at the Swiss Federal Office of Public Health.
The analysis used EPI-INFO Version $5 \cdot 0$ (Centers for Disease Control and Prevention, Atlanta, GA, USA and World Health Organisation, Geneva, Switzerland) and LOGISTIC 3.11 (GE Dallal, Andover, MA, USA) to obtain $\chi^{2}$, Mantel-Haenszel $\chi^{2}$, and the unadjusted and adjusted odds ratios (ORs).

\section{Results}

HIV test refusal rates and HIV prevalences by exposure category between July 1990 and June 1995 are presented in table 1 . Overall, refusal rates were $17.5 \%$ among heterosexuals and $16.0 \%$ among homo/bisexual men and these rates remained stable over time $\left(\chi^{2}\right.$ for linear trend $=2.3, p=0.13$ for heterosexuals and $\chi^{2}$ for linear trend $=0.4, p=0.52$ for homo/bisexual men). Total HIV prevalences among STD patients accepting an HIV test was $1.6 \%$ among heterosexuals and $22.4 \%$ among homo/bisexual men. These prevalences remained stable over time $\left(\chi^{2}\right.$ for linear trend $=0.4, \mathrm{p}=0.55$ for heterosexuals, and $\chi^{2}$ for linear trend $=0.02, p=0.90$ for homo/ bisexual men).

Table 2 Factors associated with refusing the HIV test among heterosexuals and male homo/bisexuals treated for an STD at the SNDP, Fuly 1990-Fune 1995*

\begin{tabular}{|c|c|c|c|c|}
\hline Characteristic & $\begin{array}{l}\text { Number of } \\
\text { people }\end{array}$ & $\begin{array}{l}\text { Number who } \\
\text { refused } \\
\text { HIV test (\%) }\end{array}$ & OR $(95 \% C I)$ & $\begin{array}{l}\text { Adjusted ORt } \\
(95 \% \text { CI) }\end{array}$ \\
\hline \multicolumn{5}{|l|}{ Heterosexuals: } \\
\hline Total & 2588 & $452(17 \cdot 5)$ & - & - \\
\hline \multicolumn{5}{|l|}{$\begin{array}{l}\text { Number of sexual partners } \\
\text { in the previous } 6 \text { months: }\end{array}$} \\
\hline $0-1$ & 1177 & $243(20.6)$ & $1 \cdot 0$ & 1.0 \\
\hline $2-4$ & 1046 & $151(14 \cdot 4)$ & $0.6(0.5-0.8)$ & $0.6(0.5-0.9)$ \\
\hline $5-9$ & 165 & $20(12 \cdot 1)$ & $0.5(0.3-0.9)$ & $0.6(0.3-1.0)$ \\
\hline $10+$ & 75 & $8(10 \cdot 7)$ & $0.5(0.2-1 \cdot 0)$ & $0.5(0 \cdot 2-1 \cdot 1)$ \\
\hline Unknown & 125 & $30(24 \cdot 0)$ & $1 \cdot 2(0 \cdot 8-1 \cdot 9)$ & $1.2(0.7-1.9)$ \\
\hline \multicolumn{5}{|l|}{ Source of STD infection: } \\
\hline Stable partner & 1157 & $225(19 \cdot 4)$ & $1 \cdot 0$ & 1.0 \\
\hline Casual partner & 1182 & $195(16.5)$ & $0.8(0.7-1.0)$ & $1 \cdot 1(0 \cdot 8-1 \cdot 4)$ \\
\hline Prostitute & 218 & $24(11 \cdot 0)$ & $0.5(0.3-0.8)$ & $0.7(0.4-1.1)$ \\
\hline Unknown & 31 & $8(25 \cdot 8)$ & $1 \cdot 4(0 \cdot 6-3 \cdot 3)$ & $1 \cdot 3(0 \cdot 6-3 \cdot 1)$ \\
\hline \multicolumn{5}{|l|}{ Homo/bisexuals: } \\
\hline Total & 393 & $63(16 \cdot 0)$ & - & - \\
\hline \multicolumn{5}{|l|}{ Number of sexual partners } \\
\hline $0-1$ & 80 & $10(12 \cdot 5)$ & $1 \cdot 0$ & $1 \cdot 0$ \\
\hline $2-4$ & 149 & $18(12 \cdot 1)$ & $1 \cdot 0(0 \cdot 4-2 \cdot 2)$ & $0.9(0.4-2.1)$ \\
\hline $5-9$ & 55 & $7(12 \cdot 7)$ & $1.0(0.4-2.9)$ & $0.9(0.3-2.7)$ \\
\hline $10+$ & 64 & $19(29 \cdot 7)$ & $3.0(1 \cdot 3-6 \cdot 9)$ & $2 \cdot 6(1 \cdot 1-6 \cdot 1)$ \\
\hline Unknown & 45 & $9(20 \cdot 0)$ & $1.8(0.7-4.7)$ & $1.8(0.6-4.9)$ \\
\hline \multicolumn{5}{|l|}{ Education: } \\
\hline Higher & 133 & $30(22 \cdot 6)$ & $1 \cdot 0$ & $1 \cdot 0$ \\
\hline Apprenticeship & 214 & $29(13 \cdot 6)$ & $0.5(0.3-0.9)$ & $0.6(0.3-1 \cdot 1)$ \\
\hline Basic & 37 & $1(2 \cdot 7)$ & $0.1(0.0-0.7)$ & $0.1(0.0-0.7)$ \\
\hline Unknown & 9 & $3(33 \cdot 3)$ & $1.7(0.4-7 \cdot 3)$ & $1.5(0.3-6 \cdot 8)$ \\
\hline
\end{tabular}

${ }^{\star} \mathrm{OR}=$ odds ratio; $\mathrm{CI}=$ confidence interval

†Adjusted for all variables listed in the table (plus sex and age for the heterosexuals). 
Table 2 presents factors associated with refusing the HIV test among heterosexuals and homo/bisexual men. Only factors which were significantly associated with refusing the HIV test in the univariate or multivariate analysis $(p<0.05)$ are presented in the table. Among heterosexuals, the number of sexual partners reported in the previous 6 months was the only independent predictor for refusing the HIV test in the multivariate analysis; the more sexual partners the heterosexuals reported the less likely they were to refuse the test. This association was not only observed for the 5 year time period but also when the data were stratified by year (data not shown).

Among homo/bisexual men, both the number of sexual partners reported in the previous 6 months and the level of education were independent predictors for refusing the HIV test. Homo/bisexual men who reported 10 or more sexual partners in the previous 6 months had refusal rates of $29 \cdot 7 \%$ compared with $12.5 \%$ among those reporting $0-1$ sexual partners (adjusted odds ratio of $2 \cdot 6,95 \%$ CL $1 \cdot 1-6 \cdot 1$ ). Also, the higher the reported level of education the higher the percentage of men who refused the HIV test. These associations were also observed when the data were stratified by year (data not shown).

\section{Discussion}

This study found high levels of HIV infection among heterosexuals and male homo/bisexual STD patients at the SNDP. In comparison, HIV prevalences among people attending the anonymous HIV test sites at the five university hospitals which participated in our study ranged from $0.28 \%$ to $0.51 \%$ among heterosexuals and from $2 \cdot 4 \%$ to $5 \cdot 0 \%$ among homo/bisexual men (1990-95). ${ }^{2}$ Additionally, self reported HIV prevalences among homo/bisexual men who participated in a national HIV related behavioural survey ranged from $10 \%$ to $13 \%$ between 1990 and $1994 . .^{8}$ In each of these population groups, the HIV prevalences were lower than those recorded at the SNDP.

HIV prevalences and refusal rates remained stable among heterosexuals and homo/bisexual men treated for an STD at the SNDP between 1990 and 1995. The stable HIV prevalences are consistent with trends observed in other European networks and the refusal rates observed in Switzerland $(17 \cdot 6 \%)$ were relatively high compared with other networks which used voluntary confidential HIV testing (high refusal rates were observed in Sweden (15.0\%), Germany (12.6\%), and Finland $(12 \cdot 2 \%)) .{ }^{9}$

Among both heterosexuals and homo/bisexual men, the reported number of sexual partners in the previous 6 months was significantly associated with refusing the HIV test. Interestingly, this association differed by exposure category. The more sexual partners heterosexuals reported in the previous 6 months, the less likely they were to refuse the HIV test. In complete contrast, the more sexual partners homo/bisexual men reported in the previous 6 months, the more likely they were to refuse the HIV test. Assuming that the number of sexual partners in the previous 6 months is a good marker for the overall risk of acquiring an HIV infection, it appears that low risk heterosexuals and high risk homo/bisexual men were more likely to refuse the HIV test in our study. HIV prevalences might therefore have been overestimated among heterosexuals and underestimated among homo/bisexual men.

In general, it has been found that HIV prevalences measured by unlinked anonymous testing tend to be similar or greater than those measured by voluntary confidential testing in the same population. ${ }^{510}$ Where HIV prevalences have been greater, the results have frequently been affected by a participation bias with those at increased risk of HIV infection being more likely to refuse the test. Our analysis of test refusers seems to support this gen- $\vec{\omega}$ eral finding for homo/bisexual men but not for heterosexuals (HIV prevalences in this group appear to have been overestimated). This may reflect a lower desire for heterosexuals to have an HIV test as they do not perceive they were at risk for an HIV infection (another form of par- 윽 ticipation bias) or the medical interns encouraging HIV testing in heterosexuals they consider to be most at risk (a selection bias).

In conclusion, this study suspects that the HIV prevalences were biased by HIV test $\stackrel{\mathbb{D}}{-}$ refusers and that the bias affected heterosexuals $\overrightarrow{0}$ and homo/bisexuals in different directions; .2 among heterosexuals the HIV prevalences were overestimated and among homo/bisexuals they were underestimated. Although these findings might be specific to Switzerland, simi- 气ँ lar associations might be present in other $\stackrel{\perp}{\Omega}$ European networks which use voluntary confi- $\overline{\bar{a}}$ dential testing to monitor HIV prevalences among STD patients and which have substantial refusal rates. A regular analysis of the characteristics of HIV test refusers should be an integral part of surveillance systems which use voluntary confidential HIV testing.

Swiss Network of Dermatovenereology Policlinics

This network is made up of the six polyclinics of dermatovenereology which exist in Switzerland; five at university hospitals and one at a large public hospital. The following people were responsible for the study at the policlinics: Professor T Rufli in Basle, Professor L R Braathen in Bern, Professor J-H Saurat in Geneva, Professor E Frenk in Lausanne, Professor G N Burg in Zurich, and Professor A R Eichmann at the Triemli City Hospital in Zurich. The staff working at the policlinics are City Hospital in Zurich. The staff working at the policlinics are
thanked for their precious contribution to the study. Financial support: Swiss Federal Office of Public Health, grant numbers: 90-7014, 93-7124, 94-5617.

1 Quinn TC, Cannon RO, Glasser D, Groseclose SL, Brathwaite WS, Fauci AS, et al. The association of syphilis with risk of human immunodeficiency virus infection in patients attending sexually transmitted disease clinics. Arch Intern Med 1990;150:1297-302.

2 Gebhardt $M$. Aids und HIV in der Schweiz: Epidemiologische Situation, Ende 1995. Bern: Bundesamt fur Gesundheits, 1996 (in German and

3 Paget WJ, Zimmermann H-P. Surveillance of sexually transmitted diseases in Switzerland, 1974-94: evidence of declining trends in gonorrhoea and syphilis. Soz of declining trends in gonorrhoea and syphilis. Soz
Praventivmed 1997;42:30-6.

4 Unlinked Anonymous HIV Surveys Steering Group (Chairman Mr D Podger). Unlinked Anonymous HIV Seroprevalence Monitoring Programme in England and Wales. Data to the end of 1994 . Department of Health, Public Health Laboratory Service, Institute of Child Health (London): December 1995

5 Hull HF, Bettinger CJ, Gallaher MM, Keller NM, Wilson J, Mertz GJ. Comparison of HIV-antibody prevalence in

\section{.

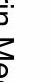


patients consenting to and declining HIV-antibody testing in an STD clinic. $¥ A M A$ 1988;260:935-8.

6 Weinstock HS, Sidhu J, Gwinn M, Karon J, Petersen LR

Trends in HIV seroprevalence among persons attending sexually transmitted disease clinics in the United States, 1988-1992. F Acquir Immune Defic Syndr Hum Retrovirol 1995;9:514-22.

7 The European Study Group. European Community Concerted Action on HIV seroprevalence among sexually transmitted disease patients in 18 European sentinel nettransmitted disease patients in

8 Dubois-Arber F, Jeanin A, Meystre-Agustoni G Moreau-Gruet F, Haour-Knipe M, Spencer B, et al. Evaluation de la stratégie de prévention du sida en Suisse. Cinquième rapport de synthèse 1993-
1995. Lausanne: Institut universitaire de médecine sociale et préventive, 1996 (Cah Rech Doc IUMSP, no 120).

9 Lavreys L, Declercq E and the European Study Group. European networks for the surveillance of HIV infections in sentinel populations of STD patients, a Concerted Action Project of the European Communities (DGXII) Brussels: Interim report June 1990-December 1994 Brussels: Interim report June 1990-December 1994.
Institute of Hygiene and Epidemiology, Brussels, June Institute of Hygiene and Epidemiology, Brussels, June
1995 .

10 Schwarcz SK, Bolan GA, Kellogg TA, Kohn R, Lemp GF. Comparison of voluntary and blinded Human Immunodeficiency Virus Type 1 (HIV-1) seroprevalence surveys in a high prevalence sexually transmitted disease clinic population. Am $\mathcal{F}$ Epidemiol 1993;137:600-8. 